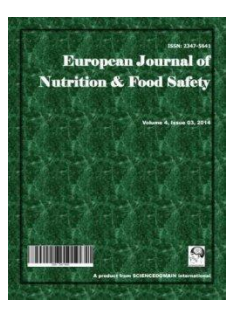

European Journal of Nutrition \& Food Safety

5(5): 400-401, 2015, Article no.EJNFS. 2015.083

ISSN: 2347-5641

SCIENCEDOMAIN international

www.sciencedomain.org

\title{
Hepcidin Screening to Guide Iron Supplementation in African Children
}

\author{
Sant-Rayn Pasricha ${ }^{1 *}$, Sarah Atkinson², Andrew Armitage ${ }^{1}$, \\ Shivani Khandwala ${ }^{1}$, Jacobien Veenemans ${ }^{3}$, Sharon Cox ${ }^{4}$, Lucy Eddowes ${ }^{1}$, \\ Theodore Hayes ${ }^{1}$, Conor Doherty ${ }^{5}$, Ayse Demir ${ }^{6,7}$, Edwin Tijhaar ${ }^{3}$, \\ Hans Verhoef ${ }^{3}$, Andrew Prentice ${ }^{4,5}$ and Hal Drakesmith ${ }^{1}$ \\ ${ }^{1}$ Weatherall Insititute of Molecular Medicine, University of Oxford, Oxford, UK. \\ ${ }^{2}$ Department of Paediatrics, Oxford University Hospitals, University of Oxford, Oxford and Oxford \\ University Clinical Academic Graduate School, Oxford, UK. \\ ${ }^{3}$ Cell Biology and Immunology Group, Wageningen University, Wageningen, The Netherlands. \\ ${ }^{4}$ MRC International Nutrition Group, London School of Hygiene and Tropical Medicine, London, UK. \\ ${ }^{5}$ MRC Keneba, Keneba, Gambia. \\ ${ }^{6}$ Royal Hospital for Sick Children, Glasgow, UK. \\ ${ }^{7}$ Laboratory for Clinical Chemistry and Haematology, Meander Medical Centre, Amsterdam,
}

The Netherlands.

Article Information

DOI: $10.9734 / E J N F S / 2015 / 20879$

Special Editors:

Lucie Bohac, Micronutrient Forum Secretariat, Canada.

Klaus Kraemer, Director, Sight and Life, Basel, Switzerland.

Chief Editor

Prof. Hans Verhagen, Senior Scientific Advisor 'Nutrition and Food Safety', National Institute for Public Health and the Environment (RIVM), P.O.Box 1, 3720 BA, Bilthoven, The Netherlands.

Conference Abstract

Received $5^{\text {th }}$ February 2015

Accepted $1^{\text {st }}$ March 2015

Published $14^{\text {th }}$ August 2015

\section{ABSTRACT}

Objectives: Hematologic and non-hematologic benefits from iron supplementation are chiefly seen in iron deficient individuals; concerns that iron might promote infection especially in non-iron deficient individuals have complicated global anemia control policies, particularly in malariaendemic settings. Iron homeostasis, including intestinal absorption, is controlled by hepcidin. Hepcidin is regulated by iron, erythropoietic drive, and inflammation, suggesting its potential utility to appraise iron status and thus guide iron supplementation.

Methods: In 1338 African pre-school children we evaluated the Area Under the ROC Curve $\left(A \cup C^{R O C}\right)$ for plasma hepcidin concentration as a diagnostic test of iron status, anemia type and erythrocyte incorporation of oral iron, determining and modeling the effects of cutoffs.

Results: Hepcidin detected iron deficiency with an $A U C^{R O C}=0.85$ (optimal sensitivity/ specificity at

Correspondence: Lucie Bohac, Coordinator, Micronutrient Forum Secretariat (email: Ibohac@micronutrient.org)

Note: This abstract was presented at "The Micronutrient Forum Global Conference - Bridging Discovery and Delivery", 2-6 June 2014, Addis Ababa, Ethiopia. 